\title{
Antenatal Care Service Utilization and Associated Factors in Fogera District, Northwest Ethiopia- a Community-based Cross-sectional Study
}

\author{
Getachew Asmare Adella \\ Department of Reproductive Health and Nutrition, College of Health Science and Medicine, Wolaita Sodo University, Wolaita Sodo, \\ Ethiopia
}

\author{
Email address: \\ gasmare35@gmail.com
}

\section{To cite this article:}

Getachew Asmare Adella. Antenatal Care Service Utilization and Associated Factors in Fogera District, Northwest Ethiopia- a Communitybased Cross-sectional Study. Journal of Gynecology and Obstetrics. Vol. 8, No. 4, 2020, pp. 91-97. doi: 10.11648/j.jgo.20200804.14

Received: June 4, 2020; Accepted: June 17, 2020; Published: July 4, 2020

\begin{abstract}
Background: Antenatal care (ANC) is the care that a pregnant woman receives while she is pregnant through a series of consultations with a trained health care provider. Adverse pregnancy outcomes can be minimized or avoided if antenatal care is received early in the pregnancy and continued through delivery. Despite it is a serious public health problem in Ethiopia, formation on the proportion and determinant factors of antenatal care service utilization is not well documented, particularly in the study area. This study aimed to identify determinant factors and the proportion of antenatal care service utilization in Fogera district, North West Ethiopia, 2019. Objectives: To assess antenatal care service utilization and its associated factors in the Fogera district, Northwest Ethiopia, 2019. Methods: Community- based cross-sectional study was conducted from December-01- to December-30- 2019 among mothers who gave live birth in the past one year before the study. Data were collected from 409 mothers using an interviewer-administered structured questionnaire. The data were analyzed manually and the chi-square test was used to describe relevant variables. Results: Antenatal care service utilization was $61.8 \%$ in the Fogera district. Variables such as age, Parity, Previous ANC visit, planned recent pregnancy, History of abortion were found to be associated with antenatal care service utilization with $\left(\mathrm{df}=2, \mathrm{x}^{2}=17.035\right.$ and $\left.\mathrm{p}<0.001\right),(\mathrm{df}=2$, $\mathrm{x}^{2}=10.50$ and $\left.\mathrm{p}<0.01\right),\left(\mathrm{df}=1, \mathrm{x}^{2}=39.7\right.$ and $\left.\mathrm{p}<0.001\right),\left(\mathrm{df}=1, \mathrm{x}^{2}=31.91\right.$ and $\left.\mathrm{p}<0.001\right)$ and $\left(\mathrm{df}=1, \mathrm{x}^{2}=6.39\right.$ and $\left.\mathrm{p}<0.02\right)$ respectively. Conclusion: In this study, the proportion of antenatal care service utilization among mothers who gave live birth in the past one year, in Fogera district was found to be $61.8 \%$ and age, parity, history of abortion, planned recent pregnancy, previous ANC visit was found to be significantly associated with antenatal care service utilization. Recommendation; Based on this research every pregnant mother should receive the recommended antenatal care visits as it is important in identifying risk factors for adverse pregnancy outcomes, both for the mother and newborn and in providing preventive and promotive health services.
\end{abstract}

Keywords: Antenatal Care, Factors, Community-based Study, Ethiopia

\section{Introduction}

Antenatal care is an important determinant of high maternal mortality rate and one of the basic components of maternal care on which the life of mothers and babies depend. [1].

Antenatal care (ANC) can be defined as the care provided by skilled health-care professionals to pregnant women and adolescent girls to ensure the best health conditions for both mother and baby during pregnancy. The components of ANC include risk identification; prevention and management of pregnancy-related or concurrent diseases; and health education and health promotion [2]. A significant number of women develop pain and bleeding in early pregnancy and require timely assessment and sensitive management in a specialist setting. Poor clinical outcomes are linked to inappropriate management It includes routine follow up provided to all pregnant women at primary care level from screening to intensive life support during pregnancy and up to delivery [3]. 
Antenatal care (ANC) is the care that a pregnant woman receives while she is pregnant through a series of consultations with a trained health care provider, i.e., midwives, nurses, and medical doctors [4]. Millennium Development Goal 5 (MDG5), calls for the improvement in maternal health, with a target of reducing the maternal mortality ratio (MMR) by three-quarters over the period 1990-2015. Ethiopia is a major contributor to maternal deaths in the world with a maternal mortality ratio of 673 per 100,000 live births and 19,000 maternal deaths annually. However, improvements have been reported about infant and child mortality reduction, there has been slow progress regarding achieving Millennium Development Goal 5 [5].

The quality of antenatal care (ANC) is dependent on the qualifications of health providers and the number and frequency of ANC visits. The content of services received and the kinds of information given to women during their ANC visits are also important components of quality care. These services raise awareness of the danger signs during the pregnancy, delivery, and postnatal period, improve the health-seeking behavior of women, orient them to birth preparedness issues, and provide basic preventive and therapeutic care [6].

Adverse pregnancy outcomes can be minimized or avoided altogether if antenatal care is received early in the pregnancy and continued through delivery (3). The World Health Organization (WHO) recommends that a woman without complications should have at least four antenatal visits, the first of which should take place during the first trimester [2]. one in every four ( 24 percent) women reported that they were informed of signs of pregnancy complications during their $\mathrm{ANC}$ visit (3).

Accordingly, the Federal Ministry of Health (FMOH) has applied a multi-pronged approach to reduce maternal and newborn morbidity and mortality by improving access to and strengthening facility-based maternal and newborn services [7].

In the year 2009/10, Ethiopia had launched a Community Based Health Care System, i.e., the Health Extension Program with the focus to improve the accessibility of family planning, safe abortions, ANC, skilled delivery and postpartum care in the community where Health Extension Workers are the Frontlines [8].

A trend analysis of the Ethiopian Demographic and Health Survey from 2000 to 2014 showed that there was a significant increase in the proportion of women who had at least one ANC from $27 \%$ in 2000 to $74 \%$ in 2019 . The increase was significant during the period 2005 to 2019 [9]. The proportion of women informed of signs of pregnancy complications varies widely by region from a low of 17 percent in Amhara to 73 percent in Addis Ababa. The proportion of women informed of signs of pregnancy complications increases with education and household wealth [10].

A cross-sectional study was done in Tigray Region, Ethiopia showed that the utilization of antenatal care service was significantly associated with marital status, education, the proximity of health facility, and husband's occupation [11]. Another study was done in Dembecha district, Ethiopia also showed that maternal age, husband's attitude, family size, maternal education, and perceived morbidity were significantly associated with antenatal care service utilization [12].

There are no studies previously conducted on mothers' antenatal care service utilization and its associated factors among mothers who gave live birth in the past one year before study in Fogera district, Northwest Ethiopia. Therefore, this study aimed to identify determinant factors and the proportion of antenatal care service utilization in Fogera district, North West Ethiopia, 2019.

\section{Methods and Materials}

\subsection{Study Design, Subjects, and Setting}

Community- based cross-sectional study was conducted from December-01- to December-30- 2019 among mothers who gave live birth in the past one year before the study. The study was conducted in the Fogera district in the South Gondar zone of the Amhara region, Ethiopia. It is located 57 $\mathrm{km}$ to the north of Bahir Dar. The district had -32- cluster kebeles. Based on clusters' 2018/2019 annual plan; its total population was estimated to be 257,160 ; of this 130,712 are males and 126448 are females. The district has 9 health centers, 45 health posts, 13 private clinics, and 1 private drug store (13).

\subsection{Sample Size and Sampling Procedure}

The sample size was determined by using the formula for a single population proportion. The following assumptions were made; $95 \%$ level of confidence, $5 \%$ margin of error, and $41 \%$ of the proportion of antenatal care service utilization in Adet district (14), and $10 \%$ of sample size were added to compensate non-respondents.

$$
\begin{gathered}
N=\frac{z^{2} \times p(1-p)}{w^{2}} \\
N=\frac{(1.96)^{2} \times 0.41(1-0.41)}{(0.05)^{2}}=372 .
\end{gathered}
$$

Adding $10 \%$ of non-response rate compensation the final sample size was 409 .

The district had a total of 32 cluster kebeles and health posts. The first three kebeles were selected by using a simple random sampling technique. Then, a list of mothers who had children less than one year was identified, using the community health management information system (CHMIS) folder list in the health posts. The name, Kebele, and Gott of each mother having children less than one year were identified and registered with the collaboration of Keeble's health extension workers by using the CHMIS family folder list. Then a simple random sampling technique with a table of random numbers was used to select study participants. All sampled mothers who had children age less than one year and lives in the area for six months during the study period were 
then interviewed at their home and three visits were done for those who were absent during the visits.

\subsection{Data Collection Procedure}

A pre-tested, structured, face-to-face intervieweradministered questionnaire was used for data collection. The questionnaire was prepared in the English language then translated to the Amharic language, and back to English by language experts to check for its consistency. Ten data collectors who had a diploma in nursing and two supervisors who had first-degree health officers were recruited to participate in data collection based on set criteria and trained for data collection and supervision. Data collectors directed questions for mothers at their homes.

\subsection{Data Quality Assurance}

To keep the quality of data, the questionnaires were pretested on $5 \%$ of the total sample size selected from one of the non-selected cluster Kebele (at Quahara Abo Kebele). The Supervisors checked the completeness of the questionnaire filled each day and he returned incomplete questionnaires to the data collector to refill by revisiting the next day.

\subsection{Study Variables}

\subsubsection{Dependent Variables}

Antenatal care service utilization.

\subsubsection{Independent Variables}

Socio-demographic characteristics such as (Age, Income, Place of residence, Occupation, Educational status, Religion, Ethnicity, etc.).

Reproductive history such as (Gravidity, parity, previous ANC visit, history of abortion, planned recent pregnancy).

\subsection{Data Processing and Analysis}

The data were analyzed manually; descriptive analysis was done with Frequencies, percentages by using tables and figures. Chi-square tests were used to identify relevant variables associated with antenatal care service utilization.

\subsection{Ethical Consideration}

Ethical clearance was obtained from the research and publication office of Rift Valley University. The committee reviewed the aforementioned project proposal with special emphasis on all ethical principles considered (respect for persons, beneficence, and justice), the objective of study ethically achievable, and method ethically sound. Then permission letter was obtained from zonal and district health offices. The questions from the questionnaire were proved not to affect the morale and personality of study participants. Informed verbal consent was obtained from each study subject after an explanation of why they take part in the research. They were also informed participation is volunteerbased. Confidentiality shall be ensured from all the data collectors, supervisors, and investigators side using code numbers than names and keeping questionnaires locked. Each respondent was assured that the information provided by them were confidential and use only for research. Moreover, there would be no risk or harm that was anticipated from the participation of the study.

\section{Result}

\subsection{Socio-demographic Characteristics of Respondents}

In this study, 409 mothers who gave live births within the past one year were interviewed with a response rate of $100 \%$. The mean age of the participants was 29 year with a standard deviation of 0.75 years. Most of the participants (79.2\%) were within the age range of 20-34 years. Almost all of the participants $(92.9 \%)$ were orthodox Religion followers and only $(3 \%)$ and $(4.1 \%)$ of responding mothers followed Protestant and Muslim religion respectively. Almost half $(54.5 \%)$ of the mothers had no education and $(56 \%)$ of respondents were housewives (Table 1).

Table 1. Socio-demographic characteristics of mothers who gave live birth in the past one year before study in Fogera district, South Gondar, Amhara Region, Northwest Ethiopia.

\begin{tabular}{llll}
\hline Variables & Category & Frequency & Percent \\
\hline \multirow{3}{*}{ Age } & $<20$ & 23 & 5.6 \\
& $20-34$ & 324 & 79.2 \\
& $35-49$ & 62 & 15.2 \\
Religion & Orthodox & 380 & 92.9 \\
& Muslim & 17 & 4.1 \\
Ethnicity & Protestant & 12 & 3 \\
Maternal & Amhara & 409 & 100 \\
education & No education & 223 & 54.5 \\
& Primary education & 165 & 40.4 \\
& Secondary education & 21 & 5.1 \\
Maternal & Housewife & 229 & 56 \\
occupation & Government & 23 & 5.6 \\
& employee & 43 & 10.4 \\
Residence & Merchant & 114 & 28 \\
\hline
\end{tabular}

\subsection{Obstetric Characteristics of Respondents}

Half of the respondents $(49.9 \%)$ have had pregnancy between 1 and 2 and $50.1 \%$ of respondents were Pregnant more than two times with the mean numbers of pregnancies 3 per woman and with a standard deviation of 0.1 pregnancies. $(63.1 \%)$ of mothers was delivered $1-2$ times. In this study $(61.8 \%)$ of women utilized ANC service. The mean numbers of delivery were 2.6 per woman with a standard deviation of 0.1 deliveries (Table 2).

Table 2. Obstetric history of mothers who gave live birth in the past one year before the study.

\begin{tabular}{llll}
\hline Variables & Category & Frequency & Percent $(\%)$ \\
\hline \multirow{3}{*}{ Gravidity } & $1-2$ & 201 & 49.1 \\
& $3-5$ & 185 & 45.2 \\
& $\geq 6$ & 23 & 5.7 \\
\multirow{2}{*}{ Parity } & $1-2$ & 258 & 63.1 \\
& $3-5$ & 138 & 33.7 \\
\hline
\end{tabular}




\begin{tabular}{llll}
\hline Variables & Category & Frequency & Percent (\%) \\
\hline \multirow{2}{*}{ History of abortion } & Yes & 49 & 12 \\
\multirow{2}{*}{ Planned recent } & No & 360 & 88 \\
pregnancy & Yes & 313 & 76.5 \\
\multirow{2}{*}{ Previous ANC visit } & Yes & 96 & 23.5 \\
& No & 239 & 58.5 \\
Current ANC visit & Yes & 170 & 41.5 \\
& No & 253 & 61.8 \\
\hline
\end{tabular}

\begin{tabular}{llll}
\hline Variables & Category & Frequency & Percent (\%) \\
\hline & None & 156 & 38.2 \\
& 1 & 134 & 32.8 \\
Number of Current & 2 & 119 & 29.1 \\
ANC visit & 3 & 71 & 17.3 \\
& 4 & 67 & 16.4 \\
& Total ANC & 253 & 61.8 \\
\hline
\end{tabular}

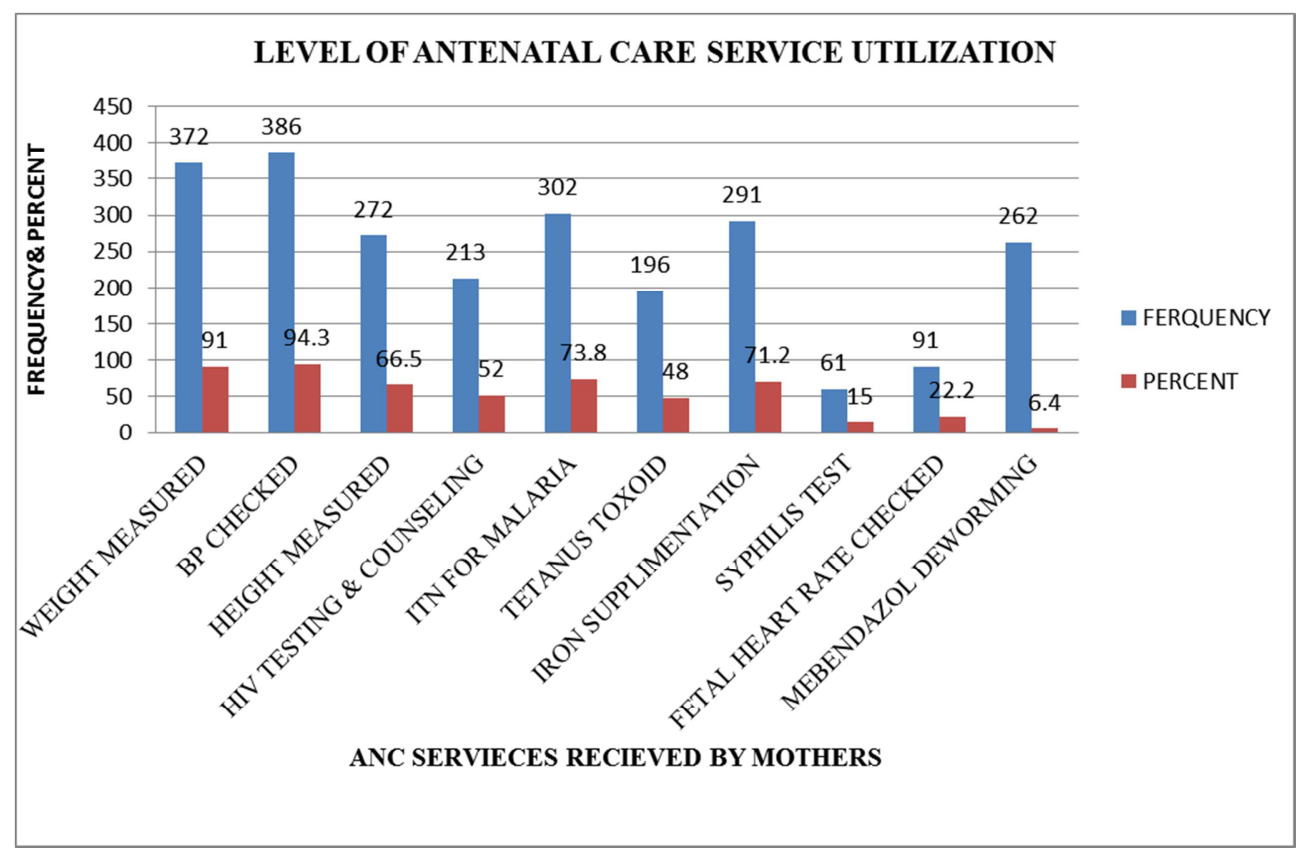

Figure 1. The frequency and percent of Antenatal Care services received by mothers who gave live birth in the past year in Fogera district, South Gondar, Amhara Region, Northwest Ethiopia.

\subsection{Chi-square $\left(x^{2}\right)$ Analysis of Factors Affecting Utilization of ANC service}

Chi-square $\left(\mathrm{x}^{2}\right)$ Analysis of factors affecting utilization of antenatal care services in table 3 indicates; age, Parity, Previous ANC visit, planned recent pregnancy, History of abortion were found to be associated with antenatal care service utilization in mothers who gave live birth in the past one year in Fogera district with $\left(\mathrm{df}=2, \mathrm{x}^{2}=17.035\right.$ and $\mathrm{p}<0.001),\left(\mathrm{df}=2, \mathrm{x}^{2}=10.50\right.$ and $\left.\mathrm{p}<0.01\right),\left(\mathrm{df}=1, \mathrm{x}^{2}=39.7\right.$ and $\mathrm{p}<0.001),\left(\mathrm{df}=1, \mathrm{x}^{2}=31.91\right.$ and $\left.\mathrm{p}<0.001\right)$ and $\left(\mathrm{df}=1, \mathrm{x}^{2}=6.39\right.$ and $\mathrm{p}<0.02$ ) respectively.

Based on the current study mothers in the age range of 20-34 years were utilized ANC service more significantly than any other age group. Mothers who deliver 3-5 times, mothers who faced abortion previously, mothers who have had previous ANC visits, and mothers who planned recent pregnancy were also utilized Antenatal care services more significantly than the other respective categories. Religion, maternal education, maternal occupation, and gravidity were found to be no association with ANC service utilization (table3).

Table 3. Factors affecting utilization of antenatal care services in mothers who gave live birth in the past year before study in Fogera district, South Gondar Amhara Region, Northwest Ethiopia.

\begin{tabular}{|c|c|c|c|c|c|c|c|c|c|c|}
\hline \multirow{3}{*}{ Variables } & \multicolumn{10}{|c|}{ utilization of antenatal care services and its associated factors using $x^{2}$ test } \\
\hline & \multicolumn{2}{|c|}{ Positive frequency } & \multicolumn{2}{|c|}{ Negative frequency } & \multirow{2}{*}{$\begin{array}{l}\text { Total } \\
\text { observed } \\
\text { frequency }\end{array}$} & \multirow{2}{*}{$\begin{array}{l}\text { Total } \\
\text { expected } \\
\text { frequency }\end{array}$} & \multirow[b]{2}{*}{ df } & \multirow{2}{*}{$\begin{array}{l}X^{2} \\
\text { tabulated }\end{array}$} & \multirow{2}{*}{$\begin{array}{l}\mathrm{X}^{2} \\
\text { calculated }\end{array}$} & \multirow[b]{2}{*}{ p-value } \\
\hline & observed & expected & observed & expected & & & & & & \\
\hline \multicolumn{11}{|c|}{ 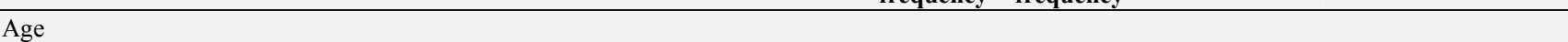 } \\
\hline$<20$ & 5 & 14 & 18 & 9 & 23 & 23 & \multirow{4}{*}{2} & \multirow{4}{*}{5.991} & \multirow{4}{*}{17.035} & \multirow{4}{*}{$<0.001 * *$} \\
\hline $20-34$ & 227 & 200 & 97 & 124 & 324 & 324 & & & & \\
\hline $35-49$ & 21 & 38 & 41 & 24 & 62 & 62 & & & & \\
\hline Total & 253 & 253 & 156 & 156 & 409 & 409 & & & & \\
\hline \multicolumn{11}{|l|}{ Religion } \\
\hline Orthodox & 241 & 235 & 139 & 145 & 380 & 380 & \multirow{5}{*}{2} & \multirow{5}{*}{5.991} & \multirow{5}{*}{2.179} & \multirow{5}{*}{$>0.2$} \\
\hline Protestant & 5 & 7 & 7 & 5 & 12 & 4 & & & & \\
\hline Muslim & 7 & 11 & 10 & 6 & 17 & 7 & & & & \\
\hline Total & 253 & 253 & 156 & 156 & 409 & 409 & & & & \\
\hline Maternal education & & & & & & & & & & \\
\hline
\end{tabular}




\begin{tabular}{|c|c|c|c|c|c|c|c|c|c|c|}
\hline \multirow{3}{*}{ Variables } & \multicolumn{10}{|c|}{ utilization of antenatal care services and its associated factors using $x^{2}$ test } \\
\hline & \multicolumn{2}{|c|}{ Positive frequency } & \multicolumn{2}{|c|}{ Negative frequency } & \multirow{2}{*}{$\begin{array}{l}\text { Total } \\
\text { observed } \\
\text { frequency }\end{array}$} & \multirow{2}{*}{$\begin{array}{l}\text { Total } \\
\text { expected } \\
\text { frequency }\end{array}$} & \multirow[b]{2}{*}{ df } & \multirow{2}{*}{$\begin{array}{l}\mathrm{X}^{2} \\
\text { tabulated }\end{array}$} & \multirow{2}{*}{$\begin{array}{l}\mathrm{X}^{2} \\
\text { calculated }\end{array}$} & \multirow[b]{2}{*}{ p-value } \\
\hline & observed & expected & observed & expected & & & & & & \\
\hline No education & 123 & 138 & 100 & 85 & 223 & 223 & \multirow{5}{*}{2} & \multirow{5}{*}{5.991} & \multirow{5}{*}{3.73} & \multirow{5}{*}{$<0.1$} \\
\hline Primary education & 114 & 102 & 51 & 63 & 165 & 165 & & & & \\
\hline Secondary education & 16 & 13 & 5 & 8 & 21 & 21 & & & & \\
\hline Total & 253 & 253 & 156 & 156 & 409 & 409 & & & & \\
\hline \multicolumn{7}{|l|}{ Maternal occupation } & & & & \\
\hline Housewife & 131 & 142 & 98 & 88 & 229 & 229 & & & & \\
\hline Government employee & 20 & 14 & 3 & 9 & 23 & 23 & \multirow{4}{*}{3} & \multirow{4}{*}{7.815} & \multirow{4}{*}{4.349} & \multirow{4}{*}{$>0.2$} \\
\hline Merchant & 32 & 27 & 11 & 16 & 43 & 43 & & & & \\
\hline Farmer & 70 & 70 & 44 & 43 & 114 & 114 & & & & \\
\hline Total & 253 & 253 & 156 & 156 & 409 & 409 & & & & \\
\hline \multicolumn{11}{|l|}{ Gravidity } \\
\hline $1-2$ & 126 & 125 & 75 & 76 & 201 & 201 & \multirow{4}{*}{2} & \multirow{2}{*}{5.991} & \multirow{2}{*}{5.008} & \multirow{2}{*}{$>0.1$} \\
\hline $3-5$ & 121 & 114 & 64 & 71 & 185 & 185 & & & & \\
\hline$\geq 6$ & 6 & 14 & 17 & 9 & 23 & 23 & & & & \\
\hline Total & 253 & 253 & 156 & 156 & 409 & 409 & & & & \\
\hline \multicolumn{11}{|l|}{ Parity } \\
\hline $1-2$ & 141 & 160 & 117 & 98 & 258 & 258 & \multirow{4}{*}{2} & & & \\
\hline $3-5$ & 108 & 85 & 30 & 53 & 138 & 138 & & & & \\
\hline$\geq 6$ & 4 & 8 & 9 & 5 & 13 & 13 & & 5.991 & 10.50 & $<0.01^{* *}$ \\
\hline Total & 253 & 253 & 156 & 156 & 409 & 409 & & & & \\
\hline History of abortion & & & & & & & & & & \\
\hline Yes & 43 & 30 & 6 & 19 & 49 & 49 & & & & \\
\hline No & 210 & 223 & 150 & 137 & 360 & 360 & 1 & 3.841 & 6.39 & $<0.02 *$ \\
\hline Total & 253 & 253 & 156 & 156 & 409 & 409 & & & & \\
\hline Planned recent pregnand & & & & & & & & & & \\
\hline Yes & 232 & 194 & 81 & 119 & 313 & 313 & & & & \\
\hline No & 21 & 59 & 75 & 37 & 96 & 96 & 1 & 3.841 & 31.91 & $<0.001 * * *$ \\
\hline Total & 253 & 253 & 156 & 156 & 409 & 409 & & & & \\
\hline Previous ANC visit & & & & & & & & & & \\
\hline Yes & 205 & 148 & 55 & 91 & 239 & 239 & & & & \\
\hline No & 48 & 105 & 101 & 65 & 170 & 170 & 1 & 3.841 & 39.7 & $<0.001 * * *$ \\
\hline Total & 253 & 253 & 156 & 156 & 409 & 409 & & & & \\
\hline
\end{tabular}

Significant at $* \mathrm{P}$ value $<0.05,{ }^{*} \mathrm{P}$ value $<0.01$ and $* * * \mathrm{P}$-value $<0.001$.

\section{Discussion}

This study revealed that $61.8 \%$ of pregnant women were received at least one ANC service in the Fogera district. The finding was in line with a study conducted in a rural area of Bangladesh, Dodoma Municipal Tanzania, Ethiopian Mini Demographic and health survey 2014 in Amhara region, Womberima woreda, Dembecha district where $62.5 \%, 60 \%$, $63 \%, 64.3 \%, 60 \%$ of mothers received ANC service respectively $[12,15-18]$. The result of this study was similar to the above studies probably the population were rural population, the educational status of those studies were similar.

The finding of this study was lower than studies conducted in Semi-urban area in Fako Division, Cameroon, rural area of Nepal, Tigray region of Ethiopia, Oromia health bureau of Ethiopia, shashemene town of Ethiopia where 99\%, 68\%, $76 \%, 73 \%, 67.4 \%$ of mothers received ANC services respectively [6, 11, 19-21]. The probable reason may be due to variation in residence as our study was conducted on a rural population whereas those studies were conducted in the urban population, the quality of services given was different, accessibility of services was different.

The finding of this study was higher than studies conducted in urban squatter of Pakistan and Ethiopian demographic and health survey 2011 in the Amhara region where $51 \%$ and $42 \%$ of mothers received ANC services respectively $[10,22]$. The variation may be due to differences in the study period, the difference in population educational status, and the quality of service.

The study identified five variables as associated factors for pregnant mothers' antenatal care service utilization:

The first variable identified was the age of the mother and the current study shows mothers in the age range of 20-34 years were utilized ANC service more significantly than any other age group. The finding was following studies conducted in Womberima Woreda, were mothers whose age was 30-34 years and $\geq 35$ were 5.10 and 5.75 times more likely to utilize ANC services compared to mothers below the age of 30 respectively [18].

The current study shows that mothers who gave birth 3-5 times were more likely to utilize ANC service than those who had 1 or 2 and $\geq 6$ births. The finding was almost the following studies conducted in Womberima Woreda, where mothers who had more than two were 5.18 times more likely to utilize ANC services than those who had two or one births [18].

The current study shows mothers who had a history of abortion were more likely to utilize ANC service compared to those who had no history of abortion. This was also the 
following studies conducted in Womberima Woreda, were rural mothers with a history of abortion were 6.01 times more likely to utilize ANC service compared to mothers with no history of abortion [18].

Mothers who have had previous ANC visits and mothers who planned recent pregnancy were also utilized antenatal care services more likely than the other respective categories. This finding was also in line with studies conducted in Womberima Woreda, were rural mothers with 3.72 and 1.92 times more likely to utilize ANC services than their counterparts were [18].

\section{Conclusion}

In this study, the proportion of antenatal care service utilization among mothers who gave live birth in the past one year, in Fogera district was found to be $61.8 \%$ and age, parity, history of abortion, planned recent pregnancy, previous ANC visit was found to be significantly associated with antenatal care service utilization. Based on this research each pregnant mother should receive the recommended antenatal care visits, as it is important in identifying risk factors for adverse pregnancy outcomes, both for the mother and newborn and in providing preventive and promotive health services.

\section{Consent for Publication}

Not applicable.

\section{Availability of Data and Material}

The datasets used and/or analyzed during the current study are available from the corresponding author on reasonable request.

\section{Competing Interests}

The authors declare that they have no competing interests.

\section{Funding}

There is no funding for this research.

\section{Acknowledgements}

We are very grateful to the Rift Valley University for giving us the ethical clearance. We are also indebted to thank Fogera district health office, kebeles administrations, and study participants for their cooperation during data collection.

\section{References}

[1] Ali SA, Dero AA, Ali SA. Factors affecting the utilization of antenatal care among pregnant women: a literature review. J Preg Neonatal Med 2018; 2 (2): 41-45. 42 J Preg Neonatal Med 2018 Volume 2 Issue. 2018; 2.
[2] World Health Organization. WHO recommendations on antenatal care for a positive pregnancy experience. World Health Organization; 2016.

[3] Care M. Standards for Maternity Care 2008.

[4] Fseha B. Assessment of Mothers Level of Satisfaction with Antenatal Care Services Provided at Alganesh Health Center Shire, North West Tigray, Ethiopia. Biomedical Journal of Scientific \& Technical Research. 2019 Mar 1; 16 (1): 11798802.

[5] Accorsi S, Bilal NK, Farese P, Racalbuto V (2010) Countdown to 2015: comparing progress towards the achievement of the health Millennium Development Goals in Ethiopia and other sub-Saharan African countries. Trans R Soc Trop Med Hyg 104: 336-342.

[6] Halle-Ekane GE, Fotabong CM, Njotang PN, et al. Quality of antenatal care and outcome of pregnancy in a semi-urban area in Fako Division, Cameroon: a cross-sectional study. Women Health Open J. 2015; 1 (2): 31-39. doi: 10.17140/WHOJ-1105.

[7] Federal Ministry of Health in Ethiopia. Annual Performance Report 2002 EFY (2009/2010).

[8] Federal Ministry of Health in Ethiopia. Health extension program implementation guidelines. Addis Ababa; 2012.

[9] Central Statistical Agency [Ethiopia] 2019. Ethiopia Mini Demographic and Health Survey 2019. Addis Ababa, Ethiopia.

[10] Ethiopian Central Statistical Agency, ICF international: Ethiopia demographic and health survey 2011.

[11] Tsegay Y, Gebrehiwot T, Goicolea I, Edin K, Lemma H, et al. (2013) Determinants of antenatal and delivery care utilization in Tigray region, Ethiopia: a cross-sectional study. Int J Equity Health 12: 30.

[12] Gedefaw M. Muche B, Aychiluhem M. Current Status of Antenatal Care Utilization in the Context of Data Conflict: The Case of Dembecha District, Northwest Ethiopia. Open Journal of Epidemiology. 2014; 4, 208-216. http://dx.doi.org/10.4236/ojepi.2014.44027.

[13] Fogera Woreda annual report on maternal and child health 2018/19.

[14] Yayew Mulugeta. Antenatal Care service utilization and its associated factors among mothers who gave live birth in the past one year in Adet Woreda, North West Ethiopia 2018.

[15] Shahjahan et al. Antenatal care services in rural Bangladesh. Southeast Asia Journal Of Public Health ISSN: 2220-9476.

[16] Moke M, Jennifer R, Oona MR. et al. high ANC coverage and low skilled attendance in a rural Tanzania district: a case for implementing birth plan intervention BMC pregnancy and Childbirth Volume10 http://www.biomedcentral.com/14712393/10/13:2010.

[17] Central Statistical Agency [Ethiopia] 2014. Ethiopia Mini Demographic and Health Survey 2014. Addis Ababa, Ethiopia.

[18] Mulat G, Kassaw T, Aychiluhim M. Antenatal Care service utilization and its associated factors among mothers who gave live birth in the past one year in Womberma Woreda, North West Ethiopia. Epidemiology (Sunnyvale).2015; S2: 003. doi: 10.4172/2161-1165. S2-003. 
[19] Ramesh Kumar Dahal. Utilization of Antenatal Care Services in the Rural Area of Nepal. International Journal of Collaborative Research on Internal Medicine \& Public Health, Vol. 5 No. 2 (2013).

[20] Oromia Regional Health Bureau annual Report of EFY2000. Finfinne, Ethiopia: 2002.

[21] Junayde A. Adamu A. Mitike M. Preferences of Place of delivery and Birth Attendants among Women of Shashemene Town, Oromia Regional State. International journal of technology enhancements and emerging engineering research, vol 2, issue 71 ISSN 2347-4289: 2012.

[22] N. Nisar, F. White. Factors affecting utilization of Antenatal Care in an urban squatter settlement of Karachi; JPMA (Journal Of Pakistan Medical Association) Vol 53, No. 2, Jan. 2008. 